\title{
Aplikasi Pembelajaran Anatomi Tubuh Manusia berbasis Android untuk Siswa Sekolah Dasar
}

\author{
Dian Nazelliana \\ Informatika, Universitas Indraprasta, Jakarta, Indonesia \\ E-mail: dosen.dian@gmail.com
}

Submitted Date: November $28^{\text {th }}, 2020$

Revised Date: January $01^{\text {st }}, 2021$

\author{
Reviewed Date: December $31^{\text {st }}, 2020$ \\ Accepted Date: January $05^{\text {th }}, 2021$
}

\begin{abstract}
SDN Beji Timur 3 is an elementary school in the Depok area. The delivery of cognitive learning material in this school using conventional methods has an effect on the effectiveness of student learning at school. Learning activities have two important elements in the form of teaching methods and learning media and the two are interrelated. The process of selecting teaching methods is also adapted to the learning media. Several aspects need to be considered in relation to the objectives of learning activities, types of tasks. Another aspect is the response of students during learning activities including student characteristics. Learning media has the main function as a tool for educators to teach that is influenced by climate, conditions, and the environment. Efforts to improve effective learning methods to accelerate the learning process so that learning materials are delivered interestingly at the right time. This study answers this learning problem by creating an Android-based learning media application to explain material about the introduction of human anatomy.
\end{abstract}

Keywords: Anatomy; Body; Human; Android; Primary school

\begin{abstract}
Abstrak
SDN Beji Timur 3 merupakan sekolah tingkat dasar yang ada di daerah Depok. Penyampaian materi pembelajaran kognitif di sekolah ini menggunakan metode konvensional berpengaruh pada keefektifan belajar siswa di sekolah. Kegiatan pembelajaran mempunyai dua unsur penting berupa metode mengajar dan media pembelajaran dan keduanya saling berhubungan. Proses pemilihan metode pengajaran disesuaikan juga dengan media pembelajarannya. Beberapa aspek perlu diperhatikan sehuungan dengan tujuan kegiatan pembelajaran, jenis-jenis tugas. Aspek lainya adalah respon dari siswa selama kegiatan belajar juga termasuk karakteristik siswa. Media pembelajaran mempunyai fungsi utama sebagai alat bantu pendidik untuk mengajar yang dipengaruhi iklim, kondisi, dan lingkungan. Upaya perbaikan metode belajar efektif untuk mempercepat proses pembelajaran supaya materi belajar disampaikan menarik dengan waktu yang tepat. Penelitian ini menjawab masalah pembelajaran tersebut dengan membuat aplikasi media pemelajaran berbasis android untuk menjelaskan materi tentang pengenalan anatomi tubuh manusia.
\end{abstract}

Kata kunci: Anatomi; Tubuh; Manusia; Android; Sekolah Dasar

\section{Pendahuluan}

Teknologi informasi ditujukan untuk membantu pekerjaan dengan menyediakan informasi dan melakukan berbagai tugas yang berhubungan dengan pengolahan informasi (Hanum \& Saifudin, 2019). Seiring dengan berkembangnya teknologi Android dalam media komunikasi dan informasi yang memberikan kemudahan dalam segala hal (Istiyanto, 2013). Sistem Operasi Android pada perangkat seluler seperti telepon pintar, dan komputer tablet (Yundatama, 2015). Sistem Oprasi ini bersifat terbuka untuk pengembang aplikasi untuk perangkat bergerak. Google Inc membeli Android Inc sebagai pengembangan untuk perangkat bergarak.

Google Play memiliki beberapa kategori untuk mempermudah penggunanya dalam menjelajahi aplikasi. Di antaranya adalah Kategori Seni, otomotif, kecantikan, bisnis, 
komik, komunikasi dan juga Pendidikan (Septarina, 2017). Contoh dari kategori Pendidikan meliputi persiapan ujian, kosa kata, belajar bahasa, alat bantu belajar dan juga game edukatif. Dalam hal ini Aplikasi di Google Play sangat membantu para pelajar untuk lebih memahami pelajaran di sekolahnya.

Sekolah memiliki banyak mata pelajaran yang perlu dikuasai oleh para pelajar, khususnya tiga mata pelajaran utama yaitu Matematika, Bahasa Indonesia, dan Ilmu Pengetahuan Alam. Materi pengajaran Ilmu pengertahuan alam berisi materi untuk mempelajari alam. Materi pengetahuan alam bagi siswa sekolah dasar bermanfaat bagi siswa untuk memiliki keterampilan proses dan minat terhadap alam sekitar. Siswa juga diharapkan bersikap ilmiah, mampu menerapkan konsep pada kehidupan serta mencintai alam. Memahami adanya kekuatan dan keagungan Tuhan salah satunya adalah memahami anatomi tubuh manusia. Pembelajaran materi pengetahuan alam di Sekolah Dasar dituntut agar tidak terlalu akademis dan verbalistik (Maisyaroh, 2016).

Pada umumnya anak-anak mengandalkan sekolah sebagai sarana pendidikan. Dalam hal ini peneliti ingin mempermudah para siwa dalam mempelajari mata pelajaran IPA khususnya Anatomi Tubuh Manusia melalui aplikasi agar para siswa dapat mengetahui fungsi dan peranan Anatomi tubuh manusia hanya dengan melalui gadgetnya (Simanungkalit, Juli 2017). Dengan pengetahuan tersebut anak-anak dapat mengetahui Struktur Anatomi tubuh manusia. Banyak sekolah masih menggunakan media alat peraga dan buku. Penelitian ini dikerjakan untuk membuat aplikasi Anatomi Tubuh Manusia demi mewujudkan media belajar yang interaktif sesuai perkembangan jaman. Pengembangan teknologi untuk dunia pendidikan mendukung kegiatan belajar diharapkan dapat meningkatkan minat anak-anak untuk mempelajari Anatomi Tubuh Manusia (Prawido Utomo, 2016). Media pembelajaran tersebut menjadi sarana pendukung dalam pembelajaran dirumah yang lebih menarik bagi anak-anak (Milda Surgani Firdania, 2016).

Pada kenyataan dilapangan, penyampaian materi pembelajaran kognitif di sekolah SDN Beji Timur 3 masih menggunakan metode mengajar konvensional yang tidak efektif dalam proses pembelajaran dikelas. Diupayakan ada perbaikan dalam metode belajar menjadi lebih efektifkan sehingga semua materi belajar dapat disampaikan secara menarik.
Adapun tujuan penelitian berupaya membuat aplikasi untuk membantu memudahkan siswa dalam mempelajari Anatomi Tubuh Manusia dengan menggunakan aplikasi Antum Lemu. Agar para siswa mendapatkan metode belajar yang efektif dan cepat dalam proses belajar.

\section{Metode Penelitian}

Suatu penelitian berjalan dengan benar dengan cara memilih suatu metode sebagai panduan kegiatan penelitian. Proses dalam pengumpulan data kemudian analisa data sampai kesimpulan hasil penelitian.

Merode observasi dalam pencarian data dengan mengamati langsung pada objek penelitian. Metode dengan melakukan Tanya jawab kepada guru dan para siswa seputar anatomi tubuh manusia yang ada dalam pelajaran IPA. Metode kepustakaan dilakukan dengan pengumpulan informasi sesuai topik permasalahan. Kegiatan ini dilakukan dengan membaca buku-buku, makalah, bahan kuliah maupun artikel-artikel. Metode penelitian lapangan yaitu metode dengan mendatangai sekolah dasar (SD) dengan melihat tanggapan para siswa tersebut Apakah mampu untuk memahami cara kerja anatomi tubuh manusia yang menggunakan android untuk bisa mengikutinya dengan baik.

\section{Perancangan Sistem}

Menggunakan metode pengajaran tertentu disesuaikan dengan media pembelajaran yang dimiliki. Penyampaian materi pembelajaran kognitif di sekolah SDN Beji Timur 3 masih menggunakan metode konvensional yang berpengaruh terhadap kegiatan belajar di kelas.

Proses pembelajaran menggunakan media pembelajaran yang tepa membanru keinginan belajar, minat menguasai pelajaran yang baru, membangkitkan motivasi, merangsang kegiatan belajar yang efisien. Pengaruh psikologis kepada siswa secara langsung berpengaruh dari proses pembelajaran tersebut. Berikuti ini adalah tahapan proses pengembangan system yang sudah di rancang dan diterapkan oleh peneliti. Tahapan perancangan ini menggunakan beberapa perangkat bantu pengembangan system diantaranya adalah menggunakan diagramdiagram. Diagram tersebut adalah gambaran secara logika bagaimana proses bisnis dalam pengambagan aplikasi. 


\section{Algoritma program aplikasi}

Algoritma merupakan metode yang tepat yang terdiri dari serangkaian langkah yang tersetruktur dan dituliskan secara sitematis, yang dikerjakan untuk menyelesaikan suatu masalah dengan bantuan komputer.

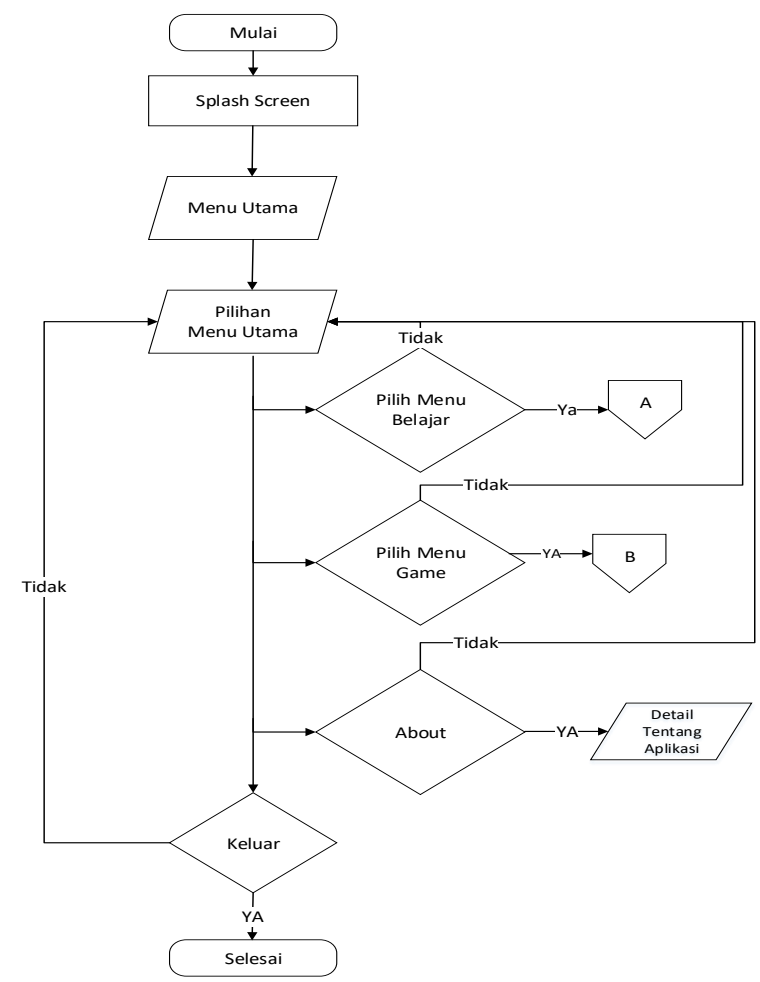

Gambar 1 Flowchart Menu Utama

Algoritma Tampilan Menu Utama pada gambar 1

a. Pada tampilan menu utama terdapat empat Button yaitu: Button Menu Belajar, Button Menu Game, Button About dan Button Exit.

b. Jika pengguna memilih salah satu Button tersebut maka aplikasi akan di alihkan ke tampilan yang dipilih.

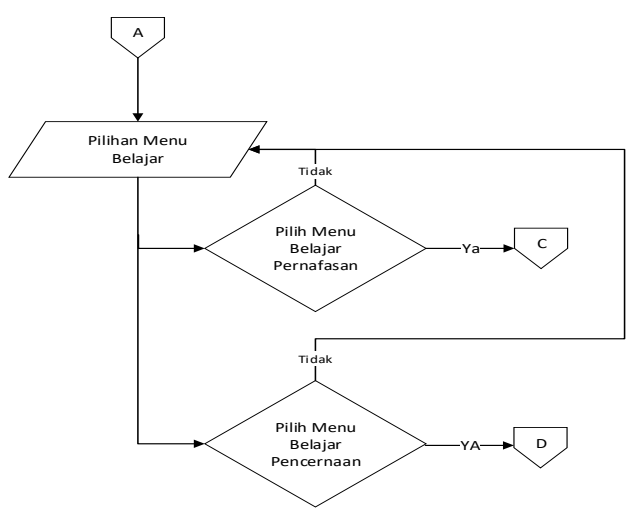

Gambar 2 Flowchart Menu Belajar
Algoritma Tampilan Menu Belajar pada gambar 2

a. Pada tampilan menu belajar terdapat dua Button yaitu: Button Menu Belajar Pernafasan dan Button Menu Belajar Pencernaan.

b. Jika pengguna memilih salah satu Button tersebut maka aplikasi akan di alihkan ke tampilan yang dipilih.

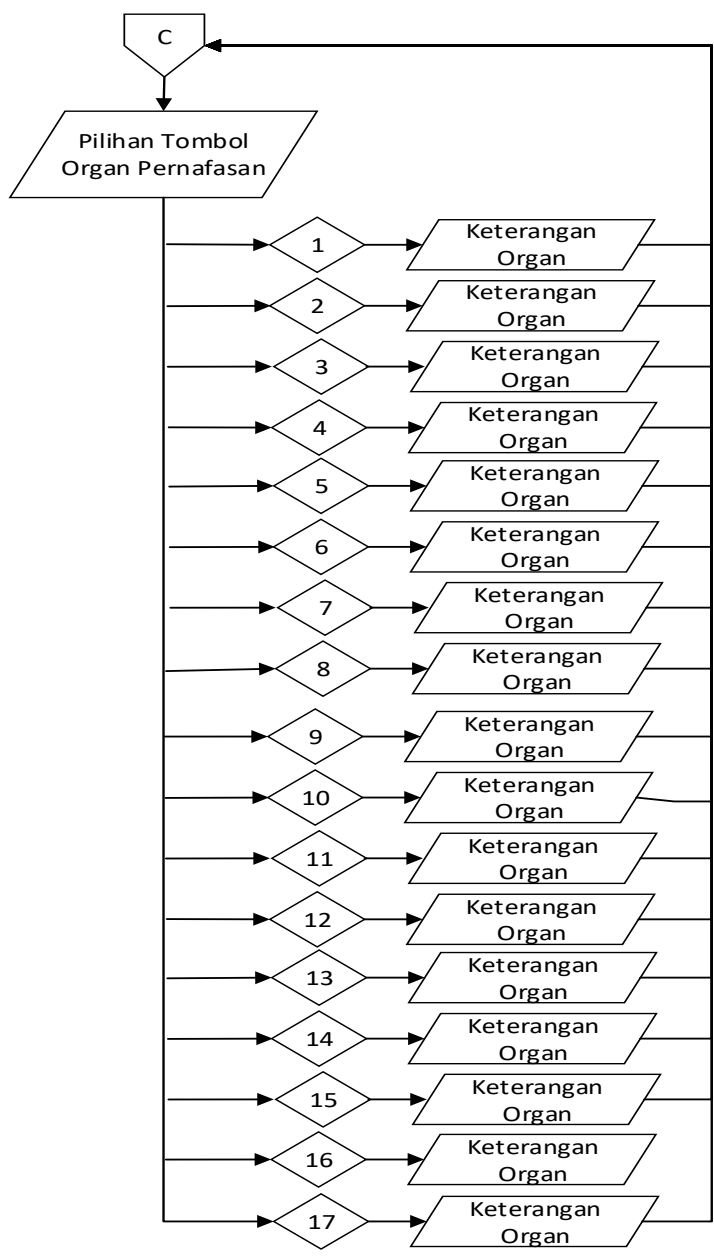

Gambar 3 Flowchart Menu Belajar Pernafasan

Algoritma Tampilan Menu Belajar Pernafasan

a. Pada tampilan menu Belajar Pernafasan terdapat tujuh belas Button yaitu: Button angka 1 sampai dengan Button angka 17.

b. Jika pengguna memilih salah satu Button tersebut maka aplikasi akan di alihkan ke tampilan yang dipilih. 


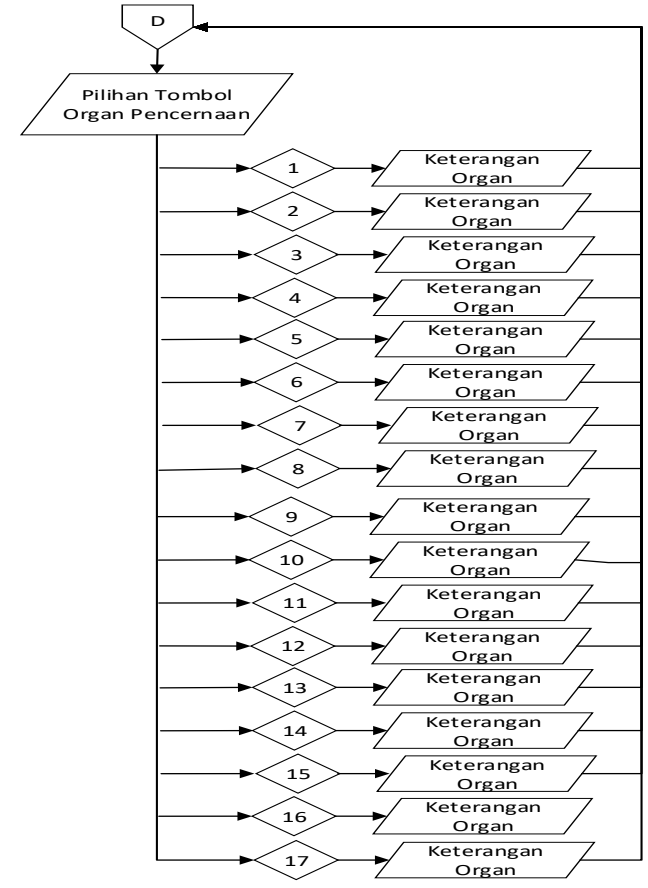

Gambar 4. Flowchart Menu Belajar Pencernaan

Algoritma Tampilan Menu Belajar Pencernaan sesuai gambar 4.

a. Pada tampilan menu Belajar Pencernaan terdapat tujuh belas Button yaitu: Button angka 1 sampai dengan Button angka 17.

b. Jika pengguna memilih salah satu Button tersebut maka aplikasi akan di alihkan ke tampilan yang dipilih.

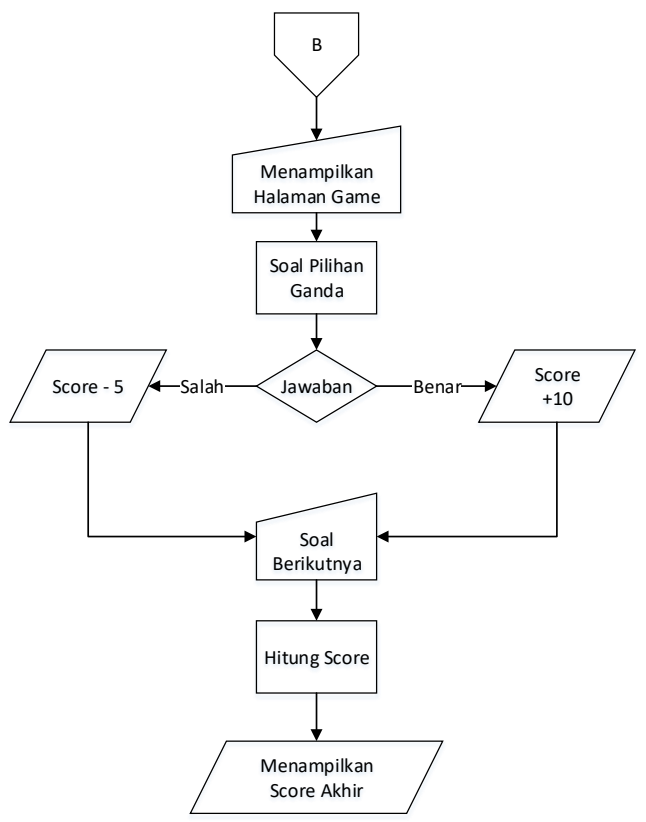

Gambar 5. Flowchart Menu Game
Algoritma Tampilan Menu Game adalah sebagai berikut:

a. Pada tampilan menu Game terdapat tiga Button Pilihan ganda yaitu: Button Jawaban 1, Button Jawaban 2 dan Button Jawaban 3.

b. Jika pengguna memilih salah satu Button tersebut maka aplikasi akan di alihkan ke tampilan yang dipilih.

\section{Rancangan Layar}

a. Tampilan Splash Screen

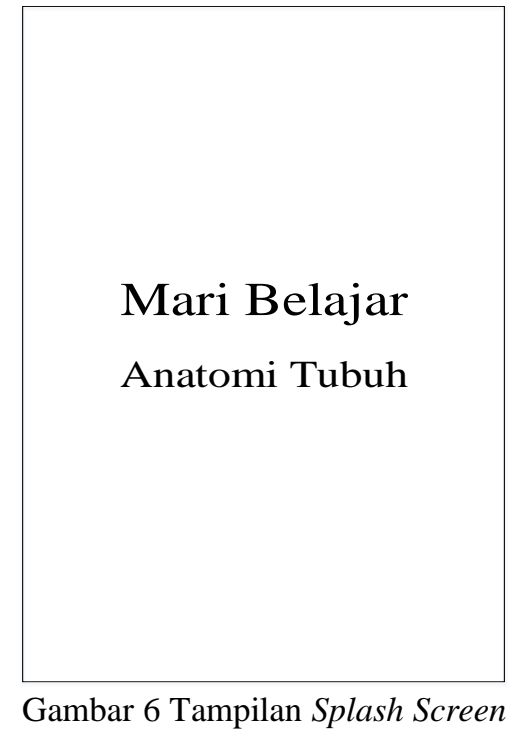

Gambar 6 adalah Tapilan awal yang pertama kali muncul saat membuka aplikasi sebelum masuk ke halaman Menu Utama.

\section{b. Tampilan Menu Utama}

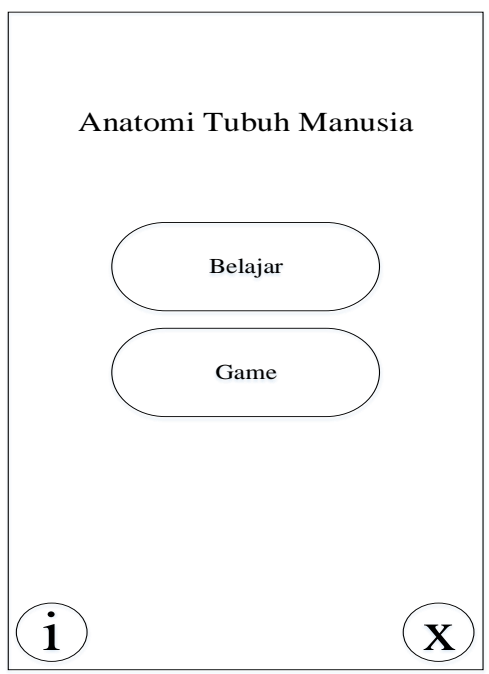

Gambar 7 Tampilan Menu Utama 
Gambar 7 adalah tampilan Pengguna memilih menu yang akan dibuka. Dengan menekan salah satu tombol menu akan menuju ke halaman yang sesuai dengan menu yang diklik.

\section{c. Tampilan Menu Belajar}

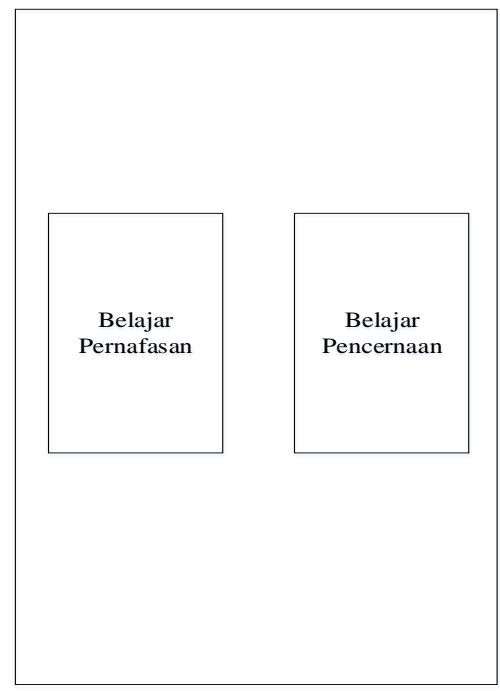

Gambar 8 Tampilan Menu Belajar

Gambar 8 adalah tampilan pengguna memilih jenis menu yang akan dibuka. Terdapat dua tombol menu yaitu Tombol menu belajar pernafasan dan Tombol menu pencernaan. Dengan menekan salah satu tombol menu akan menuju ke halaman yang sesuai dengan menu yang diklik.

\section{d. Tampilan Menu Pernafasan}

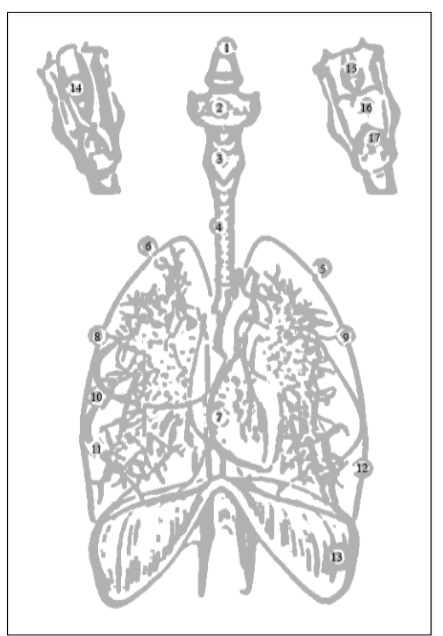

Gambar 9 Tampilan Menu Pernafasan

Gambar 9 Menunjukan halaman materi kognitif yang mana terdiri dari satu halaman gambar Pernafasan yang memiliki beberapa tombol angka yang dapat diklik untuk penjelasan gambar lebih rinci.

\section{e. Tampilan Menu Pencernaan}

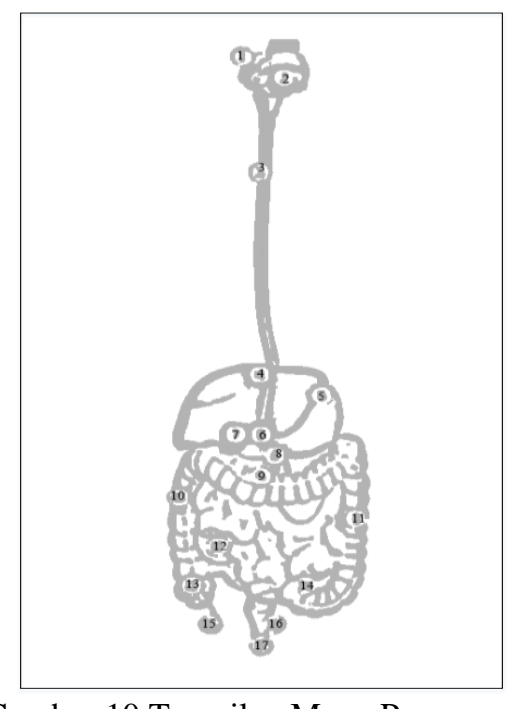

Gambar 10 Tampilan Menu Pencernaan

Gambar 10 Menunjukan halaman materi kognitif yang mana terdiri dari satu halaman gambar Pencernaan yang memiliki beberapa tombol angka yang dapat diklik untuk penjelasan gambar lebih rinci.

\section{f. Tampilan Keterangan Organ}

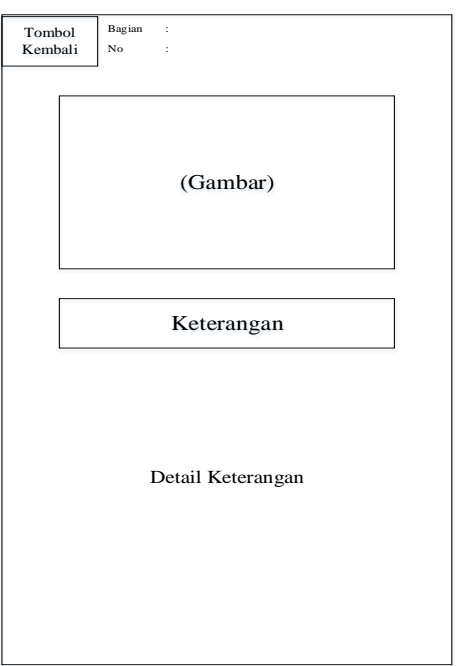

Gambar 11 Tampilan Keterangan Organ

Gambar 11 Menunjukan halaman penjelasan gambar lebih rinci dari tombol angka yang dipilih dalam Menu belajar Pernafasan dan Menu belajar Pencernaan. Berisikan Gambar detail dan keterangan dari gambar organ. 


\section{g. Tampilan Menu Game}

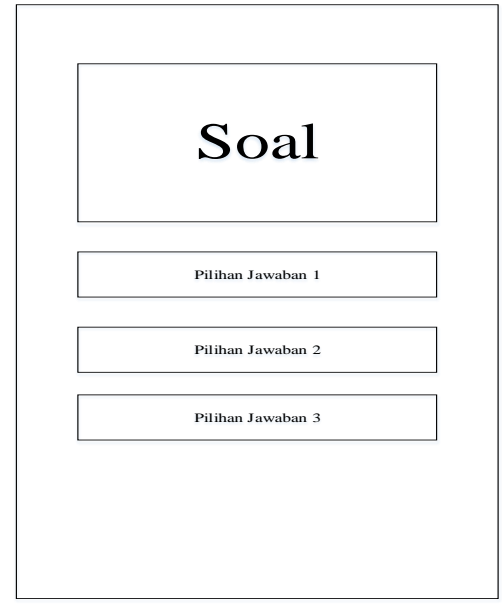

Gambar 12 Tampilan Menu Game

Gambar 12 Menunjukan halaman materi kognitif yang mana terdiri dari satu halaman gambar Pernafasan yang memiliki beberapa tombol angka yang dapat diklik untuk penjelasan gambar lebih rinci.

\section{A. Uji Coba Program dengan Contoh data}

Untuk menjamin kualitas sistem/aplikasi yang dikembangkan harus melalui tahap pengujian (Pratala, Asyer, Prayudi, \& Saifudin, 2020). Pengujian sistem bertujuan untuk memastikan bahwa semua proses sudah berfungsi sesuai dengan kebutuhan yang ditetapkan (Muslimin, et al., 2020). Pengujian terhadap perangkat lunak sangat penting dilakukan dengan tujuan untuk memberikan jaminan kualitas perangkat lunak yang dihasilkan agar bebas dari terjadinya kesalahan (Debiyanti, Sutrisna, Budrio, Kamal, \& Yulianti, 2020). Pengujian dilakukan dengan mengeksekusi aplikasi yang telah dikembangkan. Berikut ini hasil eksekusinya:

\section{Splashscreen}

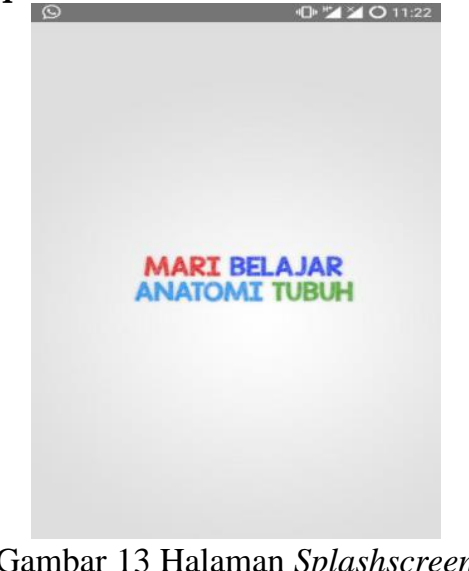

Gambar 13 Halaman Splashscreen
Gambar 13 adalah halaman ini yang pertama kali muncul saat membuka aplikasi. Halaman ini muncul sebelum masuk ke halaman Menu Utama.

\section{Menu Utama}

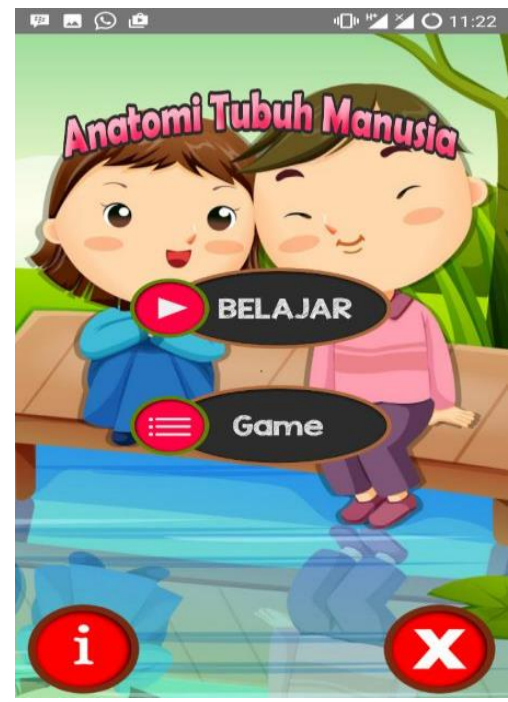

Gambar 14 Halaman Menu utama

Gambar 14 merupakan halaman untuk menampilkan tombol Menu Belajar, Menu Game, tombol About dan tombol Exit. Terdapat dua pilihan tombol yaitu belajar dan game.

\section{Menu Belajar}

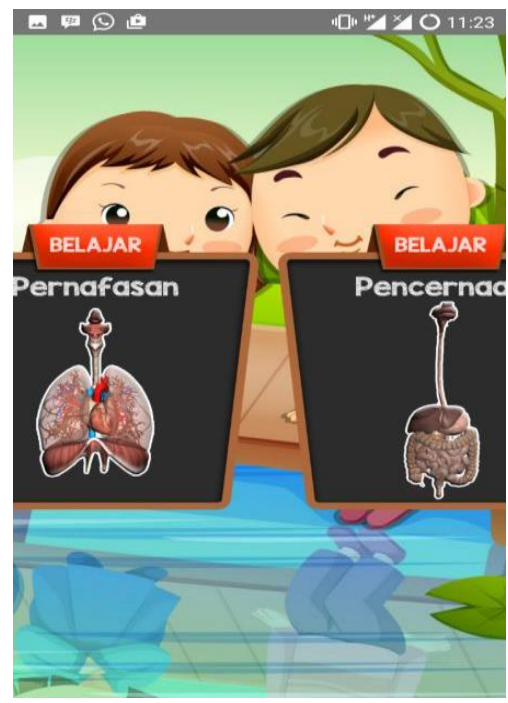

Gambar 15 Halaman Menu Belajar

Halaman ini dibuat untuk menampilkan tombol Menu Belajar Pernafasan dan tombol 
Menu Belajar Pencernaan. Pengguna diminta untuk memilih salah satu menu tersebut.

\section{Menu Belajar Pernafasan}

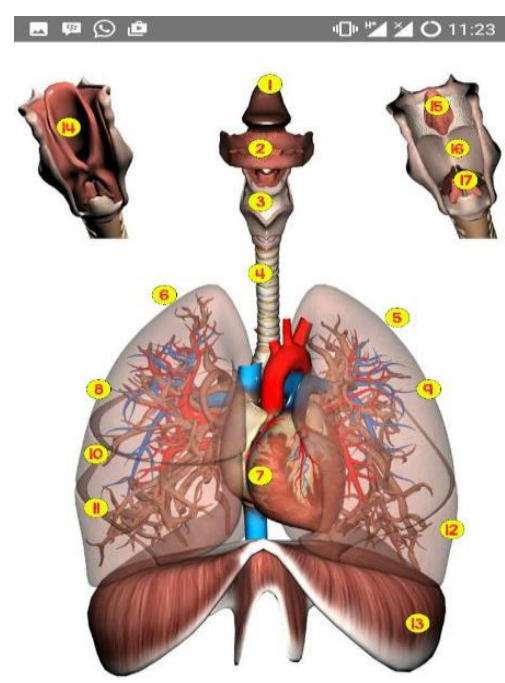

Gambar 16 Halaman Menu Belajar Pernafasan

Gambar 16 adalah halaman ini berisi gambar organ pernapasan. Terdapat tujuh belas tombol angka yang digunakan untuk berpindah ke halaman gambar organ lebih rinci.

\section{Menu Belajar Pencernaan}

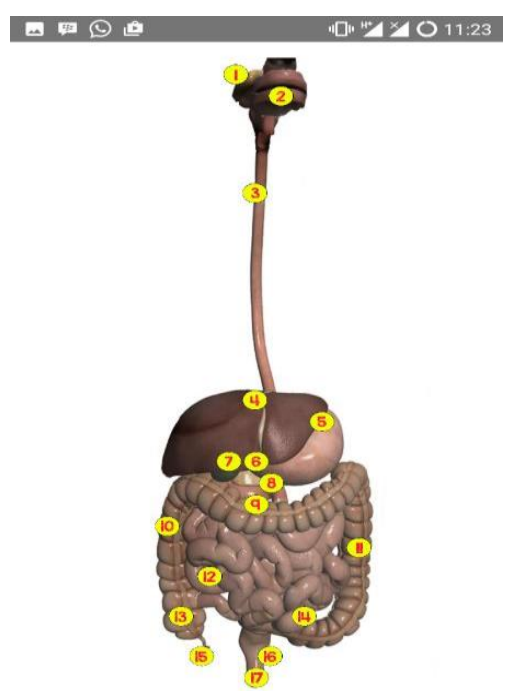

Gambar 17 Halaman Menu Pernafasan

Gambar 17 menjelaskan halaman berisi gambar organ yang terdapat tujuh belas tombol angka yang digunakan untuk berpindah ke halaman gambar organ lebih rinci.

\section{Keterangan Organ}

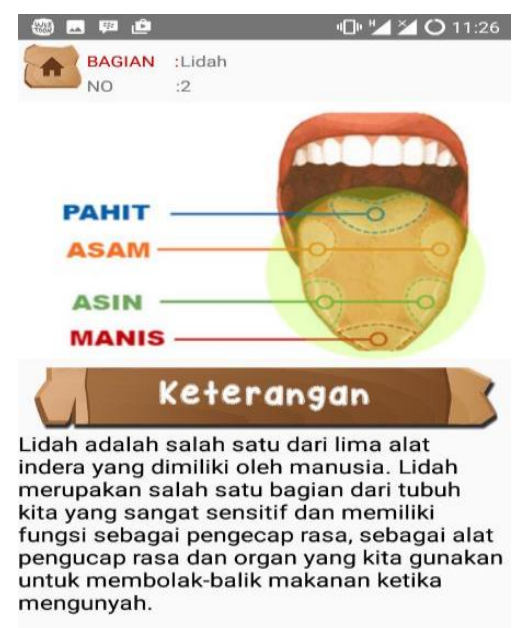

Gambar 18 Halaman Keterangan Organ

Halaman ini sesuai gambar 18 berisi gambar salah satu organ dengan keterangan rinci dari organ tersebut. Keterangan membantu pengguna memahami anatomi pada alat pencernaan manusia.

\section{Menu Game}

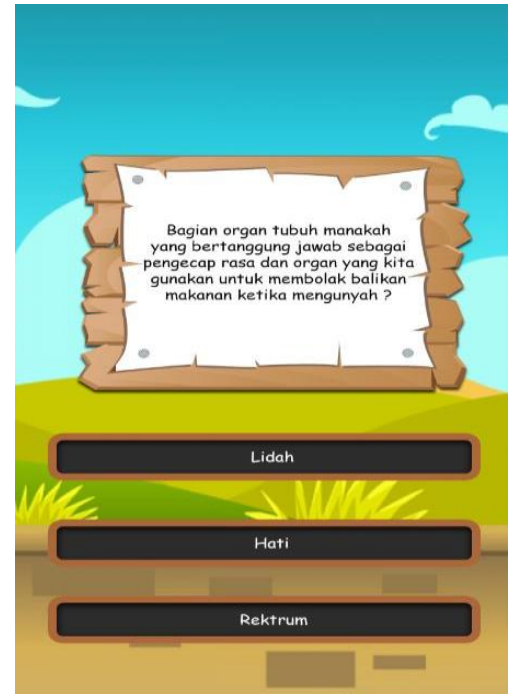

Gambar 19 Halaman Game

Halaman seuai gambar 19 ini berisi soalsoal latihan, siswa dapat memilih opsi jawaban yang dianggap benar. Selanjutnya aplikasi akan memberikan umpan balik terhadap jawaban siswa dengan memberikan aksi suara "benaaar" untuk jawaban benar dan aksi suara "yaaah salah" untuk jawaban salah. 


\section{Kesimpulan}

Program aplikasi pembelajaran anatomi tubuh manusia berbasis android untuk siswa kelas 5 SD ini dibuat dengan android studio untuk tampilan dan proses yang berjalan didalamnya. Dari penjelasan dapat menarik kesimpulan bahwa:

1. Aplikasi pembelajaran Anatomi tubuh manusia berbasis android untuk siswa SD ini memudahkan para guru dalam menyampaikan materi kognitif kepada siswa di Sekolah dasar.

2. Dengan aplikasi ini materi pembelajaran kognitif, anak anak menjadi tertarik dalam mengikuti pelajaran tersebut.

3. Aplikasi ini memaksimalkan penggunaan sarana pembelajaran yang ada di sekolah.

\section{Saran}

Aplikasi pembelajaran Anatomi tubuh manusia berbasis android untuk siswa SD ini dibuat agar anak-anak dapat memanfaatkan gadgetnya dirumah untuk belajar tidak hanya bermain game. Adapun saran lebih lanjut sebagai berikut:

1. Aplikasi ini sebaik nya selalu digunakan dalam proses belajar mengajar di sekolah, karena penyampaian materi akan lebih mudah dan efisien.

2. Aplikasi ini sebaiknya digunakan guru SD untuk melakukan penilaian pembelajaran, evaluasi, dan menindak lanjuti hasil pembelajaran kognitif.

3. Penelitian ini dapat dikembangkan dan sebagai ide kreatif untuk mata pelajaran sekolah lainya.

\section{Referensi}

Debiyanti, D., Sutrisna, S., Budrio, B., Kamal, A. K., \& Yulianti, Y. (2020). Pengujian Black Box pada Perangkat Lunak Sistem Penilaian Mahasiswa Menggunakan Teknik Boundary Value Analysis. Jurnal Informatika Universitas Pamulang, 5(2), 162-166. doi:10.32493/informatika.v5i2.5446

Hanum, W. S., \& Saifudin, A. (2019). Rancang Bangun Aplikasi Panduan Pariwisata di Kabupaten Banyuwangi Mobile Berbasis Android. Jurnal Teknologi Sistem Informasi dan Aplikasi, 2(2), 59-65. doi:10.32493/jtsi.v2i2.2798

Istiyanto, J. E. (2013). Pemograman Smartphone menggunakan SDK Android dan Hacking Android. Yogyakarta: Graha Ilmu.
Maisyaroh, M. \&. (2016). Edukasi Game Pengenalan Makanan Tradisional Indonesia Menggunakan Unityi2d. Universitas Muhammadiyah Surakarta.

Milda Surgani Firdania, T. T. (2016). Aplikasi CAI Berbasis Multimedia untuk Pengenalan Bagian Tubuh Manusia pada Anak Usia Dini. JUSTIN (Jurnal Sistem dan Teknologi Informasi), Vol 4, No 1 .

Muslimin, D. B., Kusmanto, D., Amilia, K. F., Ariffin, M. S., Mardiana, S., \& Yulianti, Y. (2020). Pengujian Black Box pada Aplikasi Sistem Informasi Akademik Menggunakan Teknik Equivalence Partitioning. Jurnal Informatika Universitas Pamulang, 5(1), 19-25. doi:10.32493/informatika.v5i1.3778

Pratala, C. T., Asyer, E. M., Prayudi, I., \& Saifudin, A. (2020). Pengujian White Box pada Aplikasi Cash Flow Berbasis Android Menggunakan Teknik Basis Path. Jurnal Informatika Universitas Pamulang, 5(2), 111-119. doi:informatika.v5i2.4713

Prawido Utomo, S. K. (2016). Aplikasi Media Pembelajaran dan Pengenalan Organ Tubuh Manusia Berbasis Multimedia. Jurnal Sisfotek Global, Vol 6, No 2.

Septarina, A. K. (2017). Perancangan Board Game Edukasi Pendidikan Moral Dengan Menggunakan Tokoh Cerita Rakyat Nusantara Untuk Usia 13-15 Tahun. Rupa Rupa.

Simanungkalit, E. (Juli 2017). Perancangan Aplikasi Pembelajaran Pengenalan Organ Tubuh Manusia Bagian Dalam Dengan Menggunakan Metode Computer Based Instruction. Jurnal Mudira Indure, Vol. 3. No.1.

Yundatama, Y. \&. (2015). E-learning English for Children Aplikasi Mobile Mengenal Alat Transportasi Berbasis Android. Prosiding PESAT. 